\title{
Arterial Bypass via the Obturator Canal
}

\author{
SAMUEL S. AHN, M.D., and ERIC DANIELS, M.D.
}

ABSTRACT The obturator bypass was initially employed to avoid the infected groin during revascularization. In the literature, placement of over 300 obturator bypass grafts has been reported for a variety of indications, although the number of procedures performed was undoubtedly much higher. Important factors that must be considered before performing such a bypass include the proper assessment of adequate inflow, outflow, and the anatomic site of infection or other complicating circumstances. Although different surgical approaches have been advocated by several authors, the technique will ultimately be determined by patient circumstances and physician resourcefulness. A recent review of the literature showed 1- and 5-year patency rates for all indications of obturator bypass to be $71 \%$ and $60 \%$, respectively. As the procedure is generally safe, this extraanatomic bypass may be used to circumvent a variety of obstacles that preclude a standard revascularization procedure. Therefore, the technique should be included in the armamentarium of the vascular surgeon.

Keywords Transobturator, bypass, extraanatomic

The epidemic of peripheral arterial occlusive disease in the United States and other developed nations continues to make revascularization of the lower extremities a common and necessary procedure. Although conventional bypass techniques and evolving endovascular procedures have served both physicians and patients well under most circumstances, extraanatomic bypasses, exemplified by the transobturator canal approach, should exist in the armamentarium of the experienced vascular surgeon when the operating circumstances are anything but conventional.

S.S.A., Professor, Division of Vascular Surgery, Director, Endovascular Program; E.D., Medical Student, Division of Vascular Surgery, UCLA School of Medicine, Los Angeles, CA.

Copyright (C) 2000 by Thieme Medical Publishers, Inc., 333 Seventh Avenue, New York, NY 10001, USA. Tel. +l(212) 584-4662. 0894-8046,p; 2000,12,2,95,102,ftx,en;pvs00068 


\section{HISTORY}

Extraanatomic bypasses have evolved to circumvent a number of complications that may plague the standard bypass revascularization of the lower extremity. Over the past 35 years, the inventiveness of vascular surgeons faced with these extenuating complications has resulted in operations such as the obturator bypass, the axillofemoral, axillopopliteal, femorofemoral, and other extraanatomic bypasses. Throughout this time, a number of investigators reported their experiences with extraanatomic bypasses. In 1978, Veith and colleagues $^{1}$ reported success with novel approaches to limb salvage by using polytetrafluoroethylene (PTFE) grafts, which crossed multiple joints in 14 patients as axillopopliteal or cross-over axillopopliteal bypasses. Other investigators have reported on similar operations..$^{2-4}$

In 1962, Shaw and Baue ${ }^{5}$ reported on the use of the obturator foramen to route the bypass because of deep groin infection in three patients. Since their initial experience, over 300 cases of obturator canal bypasses have been reported in the literature. Throughout the 1980s, a number of authors reviewed the literature and added their own experience. ${ }^{6-12}$ In 1982, Prenner and Rendl published an extensive review on 153 obturator bypasses reported in the literature. ${ }^{13}$ These authors and other investigators more recently concluded that the obturator bypass continues to be a very useful tool to accomplish arterial reconstruction in the patient with deep groin infection and with other complicating circumstances. ${ }^{14-19}$

The history of the obturator bypass and other extraanatomic bypasses demonstrates the interest of vascular surgeons in alternative approaches to revascularize with complications precluding in-line anatomic reconstruction.

\section{INDICATIONS}

There are a number of clinical circumstances that serve as grounds for the vascular surgeon to consider a transobturator approach in lower extremity revascularization. The most likely situation is documented or suspected infection of a prosthetic graft confined to the groin. This usually prevents standard limb-preserving techniques, and it has been the most common indication of obturator bypass reported in the literature. A review of the literature indicates that this technique has been performed for a variety of reasons other than graft infection. For example, Mentha and associates performed obturator bypass because of radiation-induced necrosis and vascular involvement of the groin. ${ }^{20}$ In 1970, Fromm and Lucas described five infected pseudoaneurysms of the groin following injection of heroin. ${ }^{21}$ Prenner and Rendl included three additional categories of indications beyond infection following reconstructive arterial surgery. ${ }^{13}$ These included other septic complications with vascular involvement, soft tissue or skin loss with 
involved vasculature, and primary or secondary infection of the arteries, unrelated to vascular reconstructions.

\section{TECHNIQUE}

The operative technique for the obturator bypass has been described in detail by Guida and Moore. ${ }^{22}$ Several important guidelines for the technique, however, will be included in this discussion to assist the surgeon in a successful operation.

The technique can be quite variable and complex, as the optimal approach will ultimately depend on both the extenuating circumstances of each patient (e.g., substantial groin infection), and the sound judgment of the surgeon. Despite this inherent variability, several key factors should be considered. These include proper assessment of adequate inflow, outflow, and the anatomic site of infection or other complicating circumstances. The donor artery may include the aorta, the ipsilateral or contralateral iliac arteries, or a noninfected preexisting aortofemoral bypass. The approach to the donor vessel may be carried out either retroperitoneally or transperitoneally. Although Guida and Moore favored a direct transperitoneal approach, a recent report by Sautner and colleagues reported a preference for extraperitoneal access with this technique, with 24 of 34 patients who underwent obturator bypass. ${ }^{23}$ In comparison, the transperitoneal approach offers the surgeon greater exposure than the extraperitoneal approach, a factor that may be of importance in secondary or multiple reoperations due to fibrous scar tissue formation. On the other hand, a retroperitoneal approach carries a diminished risk of peritoneal irritation, infection, and postoperative ileus. In addition, a patient's individual circumstances must be added to the algorithm. For example, a groin infection encroaching well above the inguinal ligament would make the transperitoneal approach less favorable, making the above deliberation academic.

Having dissected and secured proper inflow, tunneling of the bypass course is the next step. Tunneling through the obturator fossa presents the surgeon with the potential to damage the obturator artery, vein, and nerve. However, careful attention to the superior location of these structures within the foramen should avoid any difficulties. Although incision of the dense fascia covering the fossa should be made inferior to the neurovascular bundle, the bypass route should pass superior to the fibers of the internal obturator muscle to avoid compression of the conduit between the muscle and inferior portion of the fossa with muscular contraction. After dissecting free and assuring an appropriate distal anastomotic site (e.g., popliteal artery), tunneling should proceed posterior to the adductor longus, brevis, and magnus muscles. As stressed by Guida and Moore ${ }^{22}$, the tunneling instrument should not pass between the planes of the adductor longus and magnus muscles, as this will result in entry into the inferior portion of the femoral triangle, an area that may be contaminated and should be avoided. 
As indicated above, the exact technique of this and other extraanatomic bypasses is limited only by patient circumstances and physician resourcefulness. Therefore, it is of little surprise that investigators have reported modifications of the obturator bypass technique. For example, although a number of authors endorse proximal-to-distal tunneling as a means to achieve better anatomic control, ${ }^{24-26}$ Pearce and associates report that the instrument can be more safely passed from below. ${ }^{8}$ In addition, several authors have advocated the profunda femoris artery as the distal landing site. Atnip reported a crossover ilioprofunda reconstruction, emphasizing the profunda femoris artery as the preferred outflow tract in cases where the superficial femoral and popliteal artery are inadequate due to extensive vascular disease. ${ }^{25}$ This approach has been supported by others. ${ }^{26,27}$

\section{RESULTS}

Over the years, a number of authors have reported their results with obturator bypasses. In 1982, Prenner and Rendl reviewed 153 cases published between 1963 and 1981.13 Of the 153 cases in the literature, 91 (59\%) cases had "good" results, but no intermediate or long-term patency rate information was available. In 1981, VanDet and colleagues reviewed their experience and concluded that the obturator bypass was a useful technique for salvaging a patient's leg and, in some instances, his or her life. ${ }^{12}$ Pearce and colleagues, reporting from the Northwestern University School of Medicine, found that in five of their nine patients, graft patency was maintained to 3 years. ${ }^{8}$ In 1994, Sautner and associates published their personal experience with 34 cases and reviewed 125 cases reported in the literature since 1982.23 In their 34 cases, 26 of 34 patients underwent obturator bypass because of arterial occlusive disease. Indications in the remaining patients ranged from hemorrhage to fibrosis secondary to radiotherapy. Short-term analysis showed that graft occluded within 1 month postoperatively due to insufficient run-off. With respect to long-term results, all bypasses completed for indications other than occlusive disease remained patent at 12, 26, 34, 46, 71, and 84 months. Excluding patients with polyester grafts, those with occlusive disease who were grafted with PTFE showed 1- and 5-year patency rates of 73\% and $45 \%$, respectively. The authors' analysis of the literature showed 1 - and 5 -year patency rates for all indications of $71 \%$ and $60 \%$, respectively. If patients operated on prior to 1975 were excluded, survival rates for the entire cohort increased noticeably. ${ }^{23}$ A Medline ${ }^{\circledR}$ search reveals that, since 1994 , no additional series have been published on this topic.

When the long-term, cumulative results of the obturator bypass are measured against standard revascularization procedures such as above- and belowknee femoropopliteal grafts using autogenous and PTFE conduits, the results are comparable. In addition, the 5-year primary patency rates of the obturator bypass are similar to or exceed those of other extraanatomic bypasses such as the axillofemoral, axillopopliteal, and femoral-femoral bypasses. ${ }^{28}$ 
Table 1 Reported Complications of Obturator Bypass

\begin{tabular}{|c|c|}
\hline Intraoperative complications & Postoperative complications \\
\hline Hemorrhage 23 & Graft infection ${ }^{13}$ \\
\hline Bladder perforation 22 & Occlusion (early and late) $)^{13}$ \\
\hline Rectal perforation 29 & Muscle necrosis ${ }^{28}$ \\
\hline Injury to neurovascular bundle ${ }^{12}$ & False aneurysm of graft ${ }^{12}$ \\
\hline Bypass misplacement (vaginal transgression $)^{23}$ & $\begin{array}{l}\text { Recurrent hemorrhage } 2^{\circ} \text { to persistent } \\
\text { infection }{ }^{23}\end{array}$ \\
\hline
\end{tabular}

\section{COMPLICATIONS}

Complications from this procedure have included graft occlusion, infection, muscle necrosis, and perforation of the rectum and bladder (see Table 1). In addition, intraoperative and recurrent hemorrhage and a bypass that mistakenly transgressed the vagina have been reported in the literature. ${ }^{22}$ Although many of these complications are beyond the control of the surgeon, some authors have reported specific ways in which to treat and prevent these complications. Sautner and colleagues report treating recurrent hemorrhage by debriding and oversewing, which in two patients required a rotational muscle flap to cover the suture line..$^{23}$ The complication of muscle necrosis occurs as a result of inadequate collateral pathways with the popliteal or tibial arteries in the presence of a diseased profunda femoris in which an endarterectomy is not possible. This complication can be avoided by placing the obturator bypass to the distal segment of the profunda femoris artery. 20,27 Despite these complications, the obturator bypass generally is a safe method of alternative revascularization of the lower extremity (see Table 2).

Table 2 Obturator Bypass Results

\begin{tabular}{rccc}
\hline \# of patients & Median patency (months) & Median survival (months) & Ref \\
\hline 33 & 62 & 75 & 23 \\
5 & 5 & 5 & 28 \\
55 & $\mathrm{~N} / \mathrm{A}$ & $\mathrm{N} / \mathrm{A}$ & 10 \\
5 & 30 & 30 & 26 \\
9 & 3 & 3 & 12 \\
3 & 12 & 12 & 30 \\
8 & 18.5 & 19 & 25 \\
10 & 18 & 12 & 24 \\
10 & 3 & 33 & 13 \\
7 & 12 & 27 & 31 \\
\hline
\end{tabular}




\section{DISCUSSION}

The obturator bypass remains an uncommon procedure because, in most clinical circumstances, the standard in-line revascularization is the preferred route. In spite of its infrequency, the vascular surgeon should be familiar with the technique because the indications for obturator bypass are several in number and varied in reasoning. Although the majority of these indications do not merit debate, it is safe to claim that the primary rationale for being able to perform a successful obturator bypass remains the need for lower extremity revascularization in the face of groin sepsis. The severity of this problem, despite any advances in management, lies in the mortality rate of $17 \%$ and an amputation rate of $41 \% .{ }^{14}$ The optimal treatment of groin infection remains unclear and controversial. Many authors have advocated retention of the graft with local wound debridement and muscle flap coverage. Thomas and colleagues ${ }^{16}$ used rotational muscle flap closure in 18 patients with prosthetic graft infection. With one operative death, $15(88 \%)$ of 17 patients demonstrated healed wounds and intact grafts with a mean follow-up of 30 months. Other authors have reported similar results. In contrast, Taylor and colleagues reviewed the outcome of different treatment modalities in 17 incidences of groin sepsis involving a vascular prosthesis. ${ }^{19}$ Treatment methods consisted of irrigation, radical debridement, local rotational muscle flap coverage, obturator bypass, and excision alone. In comparison of the therapies, the authors concluded that graft removal and obturator bypass was the most effective means of treating local groin infection, but was associated with early death in two patients presenting with severe infection and active hemorrhage. In a similar study, Wood and associates ${ }^{30}$ compared the use of obturator bypass versus muscle flap coverage in the treatment of groin infection in 37 patients. The authors found that, when clinical pretreatment circumstances were similar, the outcomes were not significantly different. However, in the presence of infection plus hemorrhage, the use of the bypass resulted in a significantly increased successful outcome. Other authors have reported similar results. ${ }^{32}$

When considering an operative course of management, the surgeon should be aware of his or her alternatives beyond the obturator bypass. Alternatives include femoral artery ligation without reconstruction, reconstruction through the septic area, and other extraanatomic bypasses, including the axillopopliteal and lateral femoral bypass. Although the decision to operate or to treat conservatively is not easy, it remains evident that the obturator bypass is a safe, sucessful, and viable alternative to manage this severe complication.

The extraanatomic bypass is the vascular surgeon's tool to circumvent a variety of obstacles that preclude a standard revascularization procedure. The history and success of these atypical, alternate vascular routes are driven by the ingenuity of past and present surgeons. The obturator bypass has proven to be a successful and useful means to achieve satisfactory outcomes in the 
majority of patients. Therefore, the technique should be included in the armamentarium of the vascular surgeon.

\section{REFERENCES}

1. Veith FJ, Moss CM, Daly V, et al. New approaches to limb salvage by extended extra-anatomic bypasses and prosthetic reconstructions to foot arteries. Surgery 1978;84:764

2. Gupta SK, Veith FJ, Ascer E, et al. Five-year experiences with axillopopliteal bypass for limb salvage. J Cardiovasc Surg 1985;26:321

3. Connolly JE, Kwaan JHM, Brownell D, et al. New developments of extra-anatomic bypass. Surg Gynecol Obstet 1984;58:415

4. Ascer E, Veith FJ, Gupta S. Axillopopliteal bypass grafting. Indications, late results, and determinants of long-term patency. J Vasc Surg 1989;10:285

5. Shaw RS, Baue AE. Management of sepsis complicating arterial reconstructive surgery. Surgery 1962;53:75

6. Erath HG Jr, Gale SS, Smith BM, Deen RH. Obturator foramen grafts: The preferable alternate route? Am Surg 1982;48:65

7. Feldman AJ, Berguer R. Management of an infected aneurysm of the groin secondary to drug abuse. Surg Gynecol Obstet 1983;157:519

8. Pearce WH, Ricco J, Yao JST, et al. Modified technique of obturator bypass in failed or infected grafts. Ann Surg 1983;197:344

9. Rawson HD. Arterial grafting through the obturator foramen. Aust NZ J Surg 1986;56:127

10. Nevelsteen A, Mees U, Deleersnijder J, Suy R. Obturator bypass: A sixteen-year experience with 55 cases. Ann Vasc Surg 1987;5:558

11. Panetta T, Sottiurai VS, Batson RC. Obturator bypass with non-reversed translocated saphenous vein. Ann Vasc Surg 1989;3:56

12. VanDet RJ, Brands LC. The obturator foramen bypass: An alternative procedure in iliofemoral artery revascularization. Surgery 1981;89(5):543-547

13. Prenner KV, Rendl KG. Indications and technique for obturator bypass. In: Greenhalgh RM, ed. Extraanatomic and Secondary Arterial Reconstruction. London: Pitman Books; 1982:201-221

14. Yeager RA, Porter JM. Basic data underlying clinical decision making in vascular surgery: Arterial and prosthetic graft infection. Ann Vasc Surg 1992;6:485-491

15. Calligaro KD, Westcott CJ, Buckley RM, et al. Infrainguinal anastomotic arterial graft infections treated by selective graft preservation. Ann Surg 1992;216:74

16. Thomas WO, Parry SW, Powell RW, et al. Management of exposed inguinofemoral arterial conduits by skeletal muscular rotational flaps. Am Surg 1994;60:872

17. Samson RH, Veith FJ, Janko GS, et al. A modified classification and approach to the management of infections involving peripheral arterial prosthetic grafts. J Vasc Surg $1988 ; 8: 147$

18. Leguit $P$, van Berge Henesgouwen DP. The sartorious muscle transposition in the treatment of deep wound infection after vascular surgery in the groin. Vasa 1983;12:151

19. Taylor SM, Weatherford DA, Langan EM III, Lokey JS. Outcomes in the management of vascular prosthetic graft infections confined to the groin: A reappraisal. Ann Vasc Surg 1996;10:117-122

20. Mentha C, Launois B, Delaere J. Les pontages arteriels ilio-femoraux par le trou obturateur. J Chir 1965;90:131

21. Fromm SH, Lucas CE. Obturator foramen bypass for mycotic aneurysm in the drug addict. Arch Surg 1970;100:82

22. Guida PM, Moore SW. Obturator bypass technique. Surg Gynecol Obstet 1969;128:1307 
23. Sautner T, Niederle B, Herbst F, et al. The value of obturator canal bypass: A review. Arch Surg 1994;129:718

24. Cotton LT. Obturator canal bypass for aneurysm in the thigh. In: Greenhalgh RM, ed. Extra-anatomic and Secondary Arterial Reconstruction, lst ed. London: Pitman Books; 1982:222-227

25. Atnip RG. Crossover ilioprofunda reconstruction: An expanded role for obturator foramen bypass. Surgery 1991;110:106

26. Millis JM, Ahn SS. Transobturator aorto-profunda femoral artery bypass using the direct medial thigh approach. Ann Vasc Surg 1993;7:384

27. Royster TS, Lynn R, Mulcare RJ, et al. Dacron grafting from the aorta to the distal profunda femoris arteries via the obturator foramina. Arch Surg 1977;112:316

28. Geroulakos G, Parvin SD, Bell PR. Obturator foramen bypass-the alternative route for sepsis in the femoral triangle. Acta Chir Scand 1988;154:111

29. Sheiner NM, Sigman H, Stilman A. An unusual complication of obturator foramen arterial bypass. J Cardiovasc Surg 1969;10:324

30. Wood RFM. Arterial grafting through the obturator foramen in secondary haemorrhage from the femoral vessels. Angiology 1982;33:385

31. Buchardt Hansen HJ, Holstein P, Krough CJ. Obturator canal bypass to avoid an infected or scarred groin. In: Greenhalgh RM, ed. Extra-anatomic and secondary arterial reconstruction, lst ed. London: Pitman Books; 1982:228 
Drs. Ahn and Daniels have nicely described the uses, results, and complications of the obturator bypass. As they have stated, an arterial bypass via the obturator canal is an occasionally useful method for circumventing the femoral triangle when there is hostile groin pathology. Although originally described as a method for the treatment of infection involving an aortofemoral graft limb, it has been used in a variety of other circumstances, including crush injuries of the groin, malignancies, dense scarring, radiationinduced pathology, and infected femoral aneurysms due to illicit drug injection or medical interventions. Thus, obturator bypass is probably more often used for indications other than those for which it was originally introduced.

Patency rates are reasonably good, in part because in those instances in which the initial problem was not occlusive arterial disease, the runoff vessels are relatively disease-free.

A few technical points are worth mentioning. First, I have found it easier to perform this operation through an oblique lower quadrant retroperitoneal incision. Second, the obturator membrane is tough and not easy to penetrate bluntly; it should be incised. Third, careful attention should be paid to know where the obturator vessels and nerve penetrate the membrane. This is usually in the anterolateral portion and can be verified by identifying the obturator artery and tracing it distally. The incision in the membrane should be made away from these structures, usually anteromedially. Blind creation of an opening risks injury to the artery or vein, which can cause serious bleeding; while injury to the nerve can cause significant pain, dysesthesias, and gait disturbances. The bladder and ureter are also susceptible to injury and should be identified and avoided. Fourth, the hole in the membrane needs to be large, otherwise the graft can be constricted posteriorly by being draped over the cut membrane. For this reason, an externally supported prosthetic graft is preferable to either an autogenous or non-ringed prosthetic conduit. Fifth, it is important to be certain that the pathway for the new graft is posterior to the muscles which form the floor of the femoral triangle: adductor magnus, adductor longus, and pectineus. It is usually easier to create the proper plane by creating a tunnel beginning distally and using a long clamp or tunneler to approach the obturator membrane from inferiorly and then working from both sides when creating the opening. The retrograde passage of the tunneling instrument is facilitated by abduction and external rotation of the thigh.

J.G., Professor of Surgery, Case Western Reserve University School of Medicine; Chief of Vascular Surgery, Division of Vascular Surgery, University Hospitals of Cleveland, Cleveland, $\mathrm{OH}$.

Copyright (C) 2000 by Thieme Medical Publishers, Inc., 333 Seventh Avenue, New York, NY 10001, USA. Tel. +l(212) 584-4662. 0894-8046,p; 2000,12,2,103,104,ftx,en;pvs00069 
I support the authors' contention that obturator bypass should be in the armamentarium of all vascular surgeons. However, since it is so rarely performed I suspect that many, if not most, practicing surgeons have little or no experience with this procedure and therefore avoid using it when it would be most advantageous. Hopefully, this paper and these comments will help to change this trend. 
I thank Dr. Goldstone for sharing with us his extensive first-hand experience with the obturator bypass. His comments are poignant. The reader should pay particular attention to his pearls on the tunneling process, the most difficult and critical part of the procedure for the less experienced surgeon. One should exercise caution to avoid potentially devastating complications such as rectal, bladder, or ureteral injury and graft compression from a malpositioned tunneler. If performed properly, this procedure can provide gratifying results. 
